\title{
Mobile Technologies Applied to Hospital Automation
}

\author{
Cicília Raquel Maia Leite1,2, Glaucia R.M.A. Sizilio², Anna G.C.D. Ribeiro², \\ Ricardo A.M. Valentim ${ }^{2}$, Pedro F.R. Neto ${ }^{1}$ and Ana M.G. Guerreiro ${ }^{2}$ \\ ${ }^{1}$ Laboratory of Software Engineering, State University of Rio Grande do Norte \\ ${ }^{2}$ Laboratory of Hospital Automation and Bioengineering, \\ Federal University of Rio Grande do Norte \\ Brazil
}

\section{Introduction}

Industrial automation has been the focus of many studies owing to the need for increased production in the market and constant technological developments. Thus, the concepts of industrial automation have been incorporated into the medical area for some time, and are now being used in hospital automation. However, the hospital environment still not being properly automated and the automation that does exist is only found in a few processes. Several studies have been developed and are usually addressed most of the problems involved in processes with automation potential, such as: security, communication, reliability and performance of applications, biomedical devices, systems usability, logical and temporal consistency, among others.

With all the technological advances and current devices available, large and good projects are not only restricted to the invention of new technologies and concepts but also, and mainly, to the merging of existing technologies resulting in new ideas and devices that address problems not yet solved.

Mobile computing and portable devices, for example, are changing the relationships between human and computers, and are introducing a new form of communication based on context. According to Figueiredo (Figueiredo \& Nakamura, 2003) this new form of communication allows people to interact seamlessly with objects, computers, environments, etc. Such technological advances are a significant departure from the existing computational paradigm in which users need to interact explicitly with the systems in order to achieve the expected results.

This new paradigm, known as ubiquitous computing, named by Weiser (Weiser, 1991), has the ability to foster a different computer vision, focusing on people's daily life (and daily tasks). Its current applications and future possibilities can be utilized in an almost invisible way, allowing the user to communicate with technology without even realizing it. Thus, the processes occur for the user, as the services and interfaces are hiding the complexity of the system. 
In particular, ubiquitous medical environments are those in which technological advances such as mobile devices and wireless networks bring new opportunities for access and interaction of its users, such as access of patient information. And medical ubiquitous environments must support the mobility of its employees, given that mobility is inherent in the medical profession.

The medical field, in its constant pursuit for finding new methods of healing and improving patients' quality of life, has been, and will continue to be, a major beneficiary of Ubiquitous Computing. Although not a substitute for the direct contact between physician and patient, is increasingly becoming an essential and indispensable factor for doctor's decision-making. The current telemedicine systems provide global integration, which enables the sharing of data, images and voice from different sources and applications.

Thus, the aim of this chapter is to present new hospital automation technologies, specially, mobile techniques and a survey of a number of state of the art studies. Additionally, we will present an example of architecture for processing, monitoring patient's vital signs using artificial intelligent technique as logic fuzzy.

This chapter is organized as follows: Section 2 describes a brief introduction of the technologies involved with the state of art and mobile technologies applied in hospital automation. In Section 3 presented the architecture and its components by for example of an architecture with Intelligent and Mobile Technology. In Section 4 presented all the valdation of the architeture with focus on the constraints that must be obeyed when it comes to patient monitoring. Finally, in the Section 5 the conclusions are presented.

\section{Mobile technologies applied in hospital automation}

\subsection{An overview of hospital automation}

The automation can be considered a multidisciplinary area involving: programming languages (software), electronic platforms (hardware) and actuators (mechanical). This factor means that studies in automation are comprehensive and therefore involve a wide range of knowledge (Nof, 2009).

The hospital automation is a subfield of automation that seeks to promote the automation of processes relevant to the hospital environment, looking for efficiency and productivity and considering mainly the features and constraints peculiar to the medical environment (eg, the acquisition of data should be provided with privacy in order to ensure the ethics of the medical act and preserve the integrity of the patient) (Feng, 2007).

Typically, the hospitals make use of technologies that provide greater security, reliability, robustness to the daily tasks, mainly because they deal with human lives. As an example, we can mention applications (hardware / software), relating to Fig. 1.

- management and control: electronic medical records, appointment scheduling, control of pharmacy, hospitalization, laboratory, among others;

- communication: tracking patients, staff and materials;

- medical equipment and laboratory devices: cardiac monitors, pulse oximeter, stethoscopes, thermometers, surgical tools, magnetic resonance, scanner, among others;

- monitoring: patients, staff and materials;

- helping medical diagnosis: according to each specialty. 
Integrating the hospital environment are the ICUs, defined as hospital units for the care of critically. The scope of work includes the monitoring of vital signs of patients in the ICU, aiming at the realization of pre-diagnostic to help medical decision and providing information to send alerts when needed.

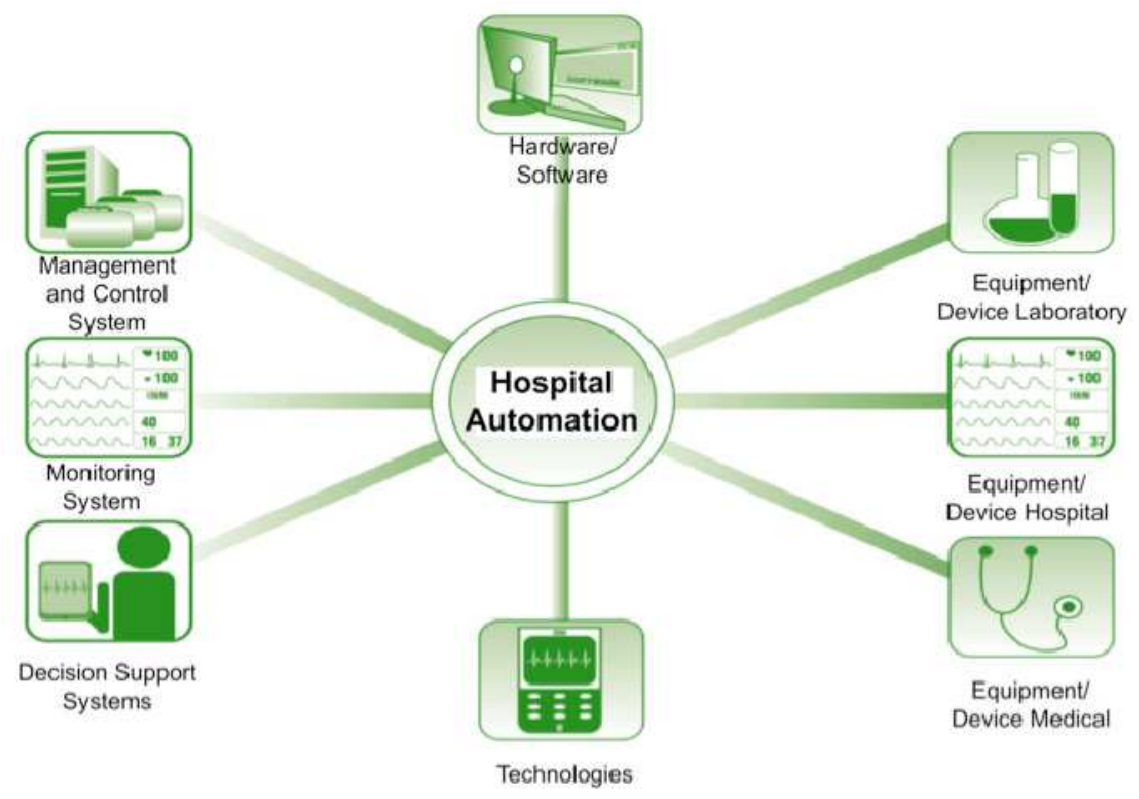

Fig. 1. Hospital Automation

According to Hoerr (Mosby's, 2010) "the patient is any individual under medical care." Particularly, patients in the ICU need care, company and continuous monitoring of vital signs, aimed at early detection of risk situations, allowing timely intervention by health professionals monitoring of vital signs, to early detect risk situations, allowing timely intervention by medical staff. Some patients are admitted because they present a severe clinical manifestation and others are admitted only for monitoring of vital signs because they underwent surgery, for example. So, the automation process of the ICU becomes necessary in order to minimize errors and maximize available resources to the medical team for the patients' care and monitoring.

Vital signs are measurements that provide physiological data indicating the health conditions of the person, demonstrating the functioning and changes in body function. Thus, the vital signs guide the initial diagnosis and the monitoring of patients' clinical evolution. So, their main objective is to help in the health assessment of the person, as well as equip the decision making process related to specific interventions. The vital signs monitored that help the medical diagnosis are: systolic blood pressure, diastolic blood pressure, mean arterial pressure, heart rate, respiratory rate, body temperature and partial oxygen saturation, as shown in Table 1 (Jauch et. al, 2010). The correct measurement of vital signs is extremely important for the clinical assessment of patients that are, in this work scope, in the ICU. 


\begin{tabular}{|c|c|c|}
\hline Name & Abbreviation & Normal Value \\
\hline Pressure (Systolic / Diastolic) * & Bp & $\begin{array}{c}04 \text { years old }-85 / 60 \mathrm{mmHg} ; \\
06 \text { years old-95/62 } \mathrm{mmHg} ; \\
10 \text { years olsd }-100 / 65 \mathrm{mmHg} ; \\
12 \text { years old }-108 / 67 \mathrm{mmHg} ; \\
16 \text { years old }-118 / 75 \mathrm{mmHg} ; \\
\text { Adults }-120 / 80 \mathrm{mmHg} ; \\
\text { Elderly }-140 \text { a } 160 / 90 \text { to } 100 \mathrm{mmHg} .\end{array}$ \\
\hline $\begin{array}{c}\text { Heart rate } \\
\text { (The objective is to evaluate } \\
\text { whether the heart is beating, and if } \\
\text { he does so with appropriate pace } \\
\text { and frequency.) }\end{array}$ & $\mathrm{Hr}$ & $\begin{array}{l}\text { Newborn - } 100 \text { a } 160 \text { bpm } \\
\text { Children - } 80 \text { a } 120 \text { bpm } \\
\text { Adult - } 60 \text { to } 100 \text { bpm }\end{array}$ \\
\hline $\begin{array}{l}\text { Respiratory Rate } \\
\text { (Through rhythm, sound and } \\
\text { depth, it reflects the metabolic state } \\
\text { of the body, the condition of the } \\
\text { diaphragm and chest muscles, } \\
\text { supplying oxygen (O2) to the } \\
\text { respiratory tract and alveoli.) }\end{array}$ & RR & $\begin{array}{l}\text { Newborn- } 30 \text { to } 60 \mathrm{mrpm} \\
\text { Children- } 20 \text { to } 30 \mathrm{mrpm} \\
\text { Adult- } 12 \text { to } 20 \mathrm{mrpm}\end{array}$ \\
\hline $\begin{array}{c}\text { Body Temperature } \\
\text { (It represents the balance between } \\
\text { heat production and heat loss.) }\end{array}$ & Bt & $\begin{array}{l}\text { Axillary: } 360 \mathrm{C} \text { to } 370 \mathrm{C} \\
\text { Oral: } 36,20 \mathrm{C} \text { to } 37,20 \mathrm{C} \\
\text { Rectal: } 36,40 \mathrm{C} \text { to } 37,40 \mathrm{C}\end{array}$ \\
\hline $\begin{array}{l}\text { Partial oxygen saturation } \\
\text { (It represents the partial oxygen } \\
\text { saturation in the blood.) }\end{array}$ & POS2 & $\begin{array}{c}\text { Low- } 0-94 \% \\
\text { Normal- } 95-100 \%\end{array}$ \\
\hline
\end{tabular}

*MBP - Mean Blood Pressure

Table 1. Key parameters for patients' vital signs analysis Sample table title

\subsection{Technology trends for hospital automation}

The development of technologies for health care are becoming a recurring term in the research field, whether the field of Engineering, Exact Sciences, Health or Human Sciences. This aspect characterizes the development of technology in health as a transversal element, or even transdisciplinary, for whose purpose is to study innovation in health usually permeate the border areas of knowledge, a factor that almost require interdisciplinary or transdisciplinary (Guimarães, 2004).

Technological innovation in health for emerging countries can be a significant tool for socioeconomic development, for two primary reasons (Marziale, 2004):

Instrumentation in order to encourage improvements in the quality of population health, democratizing and universalizing access to health care;

Generation of products with high added value. This represents a very important artifact because it can help to improve the balance of trade balances, with the reduction of royalty payments, increase of exports and job creation. 
In this sense, it is important to be delimited by prospective studies that may indicate demands actually required for the productive sector in the health area, this at the local and global sense. Thus, it becomes more consistent the strengthening of research, as well as the integration of these in the market for technological innovation in health, which is fundamental to ensure the economic sustainability of investments in research in this area (ABDI, 2008).

Technological innovation in health has many nuances and therefore can be classified in several areas, but essentially there are two sectors that are gaining greater space and visibility in the academic and corporate: The Health Informatics and Biomedical Engineering.

- Health Informatics: This is a field where the study is focused primarily on research and development and technological innovation in health from the perspective of computing applied in the medical field.

- Biomedical Engineering: is more focused on the development of medical equipment. Indeed, one can say that it is application of some areas of engineering (Mechanical and Electrical) in the health system.

In this context, there is a set of latent demand for health, and some emerging countries have realized that state. Thus, raising prospects in the following strategic areas (ABDI, 2008):

- Medical Imaging, focusing on Digital Radiology and Ultrasound;

- Hemodialysis, focusing on machines and filters;

- Neonatal, focusing on incubators for newborns;

- Medical Equipment based in Optics: Scopes and similar.

These demands are positioned as strategies because they generally take based on the trade balance and is guided by national policies for industrial development. For example, in the countries of Latin America, especially Brazil, in the year 2011 have been developed papers with following topics (R-BITS, 2011):

- Hospital Automation;

- Hospital Management;

- Telemedicine and Telehealth;

- Medical Equipment;

- Biomedical Signal Processing;

- Intelligent Systems Applied to Health;

- Medical Image Processing;

- Neuroscience;

- Rehabilitation and Assistive Technologies;

- Biomaterials and Implants.

The World Health Organization (WHO) (OMS, 2009) definition of Telemedicine involves the provision of services related to health care, where distance is a critical factor; such services are provided by professionals at health institutions using Information and Communication Technology (ICT) for the exchange of information valid for diagnosis, prevention and treatment of diseases and the continuing education of health services providers, as well as for research and evaluation. 
The telemedicine applications can be classified into five main types: telemonitoring, teletherapy, teledidactics, social telephony and telediagnosis (EDUMED, 2008) and(Shen et al, 2007).

Telediagnosis, object of this work, is characterized by remote transmission of data, from vital signs to laboratory data and medical images, among others, as well as remote consultations to patients with the objective of diagnostic decision-making among medical specialists. In this area can be envisioned remote collaborative diagnosis and second opinion scenarios, which can be defined as an additional consultation with another physician or medical group, requested by the patient or the doctor who is seeing the patient, in order to guarantee the correct diagnosis.

Noting, therefore, important advances in health, especially when it comes to innovation, perhaps the greatest challenge is to automate processes without losing the axis of the humanization of health services, i.e. automating to humanize. This is because innovation in health care is already doing this in contemporary societies, research has expanded and is contributing to the breaking of paradigms in this area, bringing to light new knowledges, and therefore the biggest concern is not losing focus on patient.

\subsubsection{Intelligent systems techniques}

Because of the globalization, technological revolution, fast acess to information and efficient management, the market and companies start to demand the development of intelligent computational systems. Thus, the technology becomes the central attention of this revolution with the internet, softwares, hardwares and communications. Some challengers start to appears because of the needs listed in the previous sections, as:

- $\quad$ Acess to relevant data;

- Identify opportunities;

- Fast Action and re-action;

- Manipulation of high amount of data and information;

- Simulation of new methods, process and technology.

The advances in artificial intelligence, in parallel computation and the evolution in the communications, as the internet, have contributing for the development of new ystems capable of bring new way of processing. Adding value and advantages to this systems.

Intelligent Systems (IS) have important characterisitcs, as: ability to store, adapt and modify their context to solve problems, tasks in an automatic way, the capacity to make associations and inferences to solve complex real problems (Rezende, 2003).

For a system to be consider intelligent, the architecture of the system should have some characteristics as:

- It should have a set of abilities;

- Models specifics tasks.

The intelligent systems have some special techniques that can be used together or not. Artificial neural networks, fuzzy logic, evolutionary computation are some of the main techniques used in SI (Hanson, C. e Marshall, 2001). There are three sub-areas (supervised 
learning, evolutionary and hybrid) that are the core of intelligent systems. There are others importants paradigms as unsupervised learning, reinforced learning, simbolic learning and cognitive sciences (Shavlik e Dietterich, 1990). The Fig. 2 shows the relation between this three sub-areas and their core. They were develped in the beginning of the sixties as the perceptron (Rosenblatt, 1958); the fuzzy logic (Zadeh, 1965, 1973; Zadeh et al, 2002.); and genetic algorithms (Barricelli, 1954; Fraser, 1957).

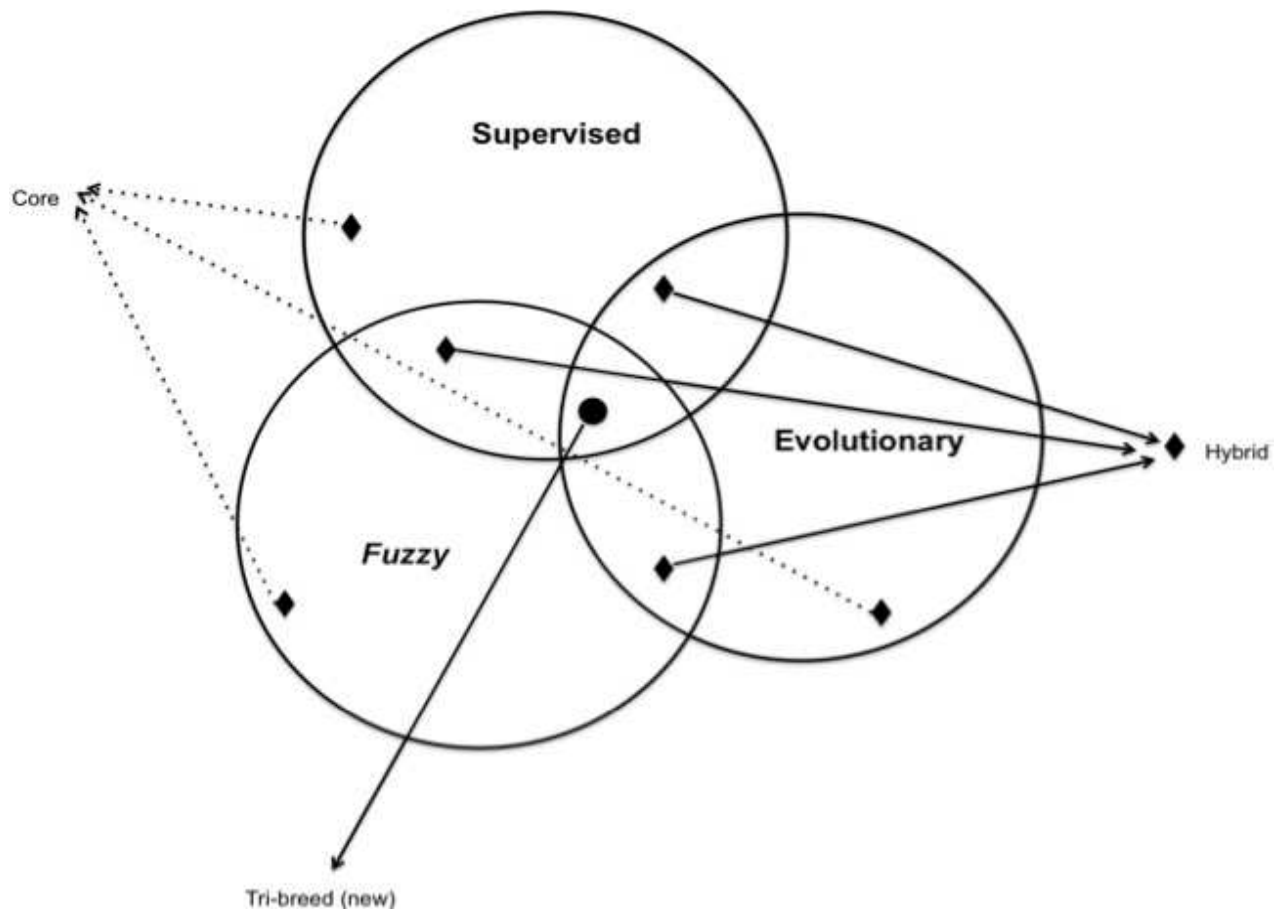

Fig. 2. The main paradigms of computational intelligence. Begg (2007)

It is already known that intelligent systems are efficent tools to deal with high amount of data, and these systems have been used in healthy systems and in pre-diagnostic systems.

\subsubsection{Mobile and wireless techniques}

Ubiquitous computing aims to make human-computer interaction invisible, i.e., integrating computing with personal actions and behavior (Sousa, 2002).

Ubiquitous computing (Fig. 3) is defined as the junction of two other concepts that are: Mobile Computing, where a computing device and its services can be relocated while they are connected in a network or the Internet. The other is the Pervasive Computing, in which computing devices are distributed in the environment in a seamlessly way (Weiser, 1996). And the Fig. 4 represents the users ubiquitous interfaces. 


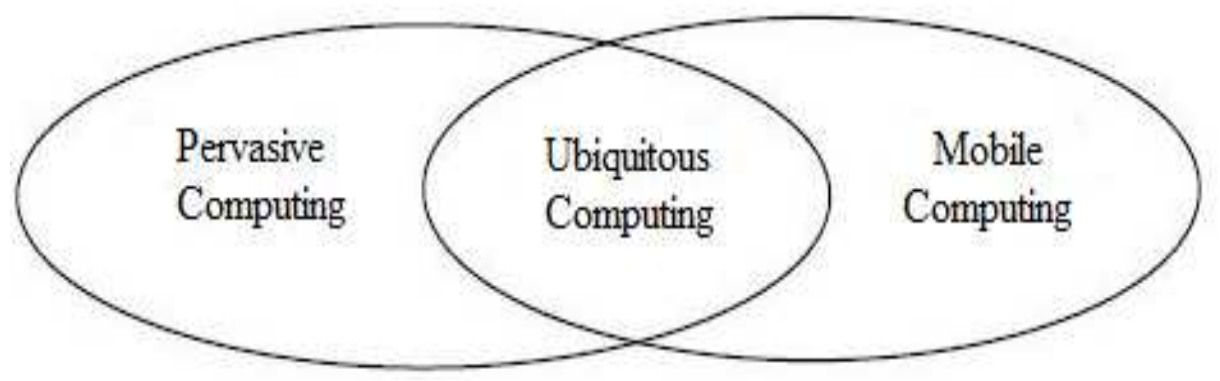

Fig. 3. Ubiquitous computing.

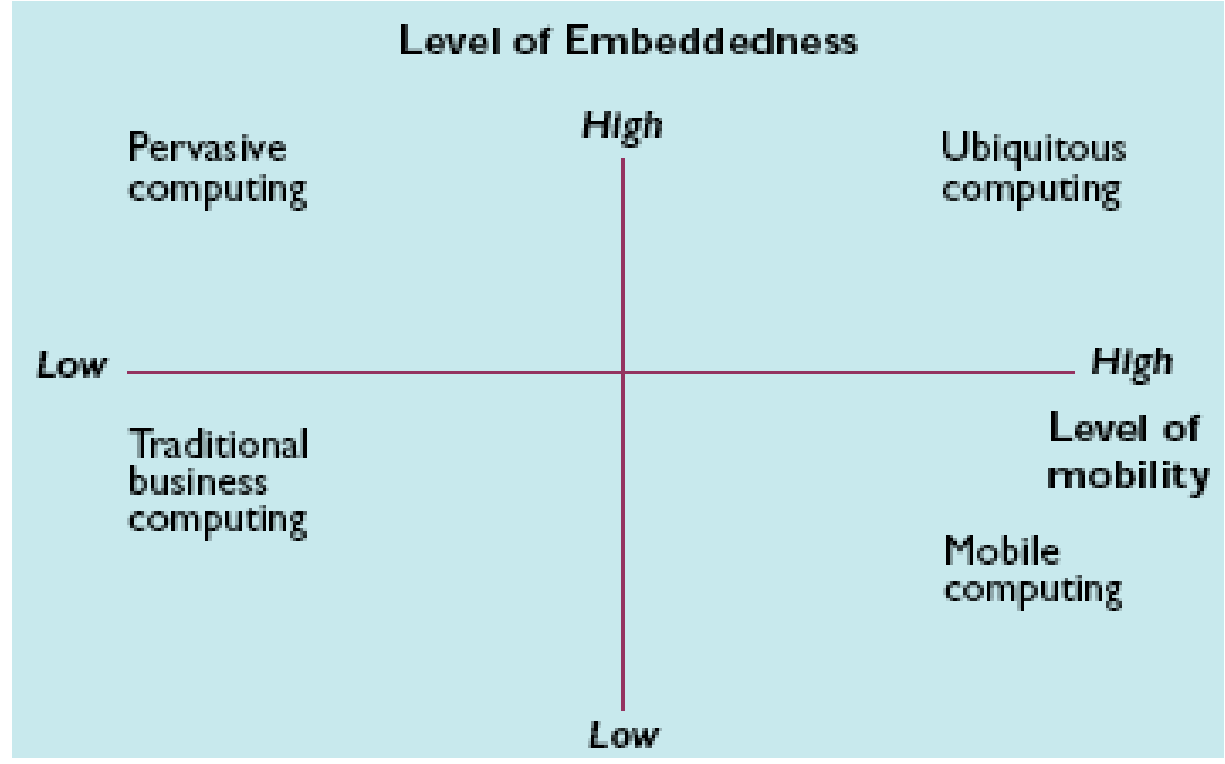

Fig. 4. User Ubiquitous Interface

Mark Weiser (Weiser, 1996) proposal is becoming a reality, through technologies such as PDAs, smart-phones, and the consolidation of wireless networking standards such as Bluetooth and IEEE 802.11. With ubiquitous computing, the relationship between users and computing devices changes compared to personal computers, what it was one to one, happens to be one to many (one user to multiple devices).

In addition to mobility, ubiquitous systems support interoperability, scalability, among other things to ensure that users have access when they want (Fig.5). According to Saha and Mukherjee (Saha \& Mukherjee 2003), advances in technology necessary to build a ubiquitous computing environment are: devices, interconnection network, middleware, and applications. 


\section{UBIQUITOUS COMPUTING}

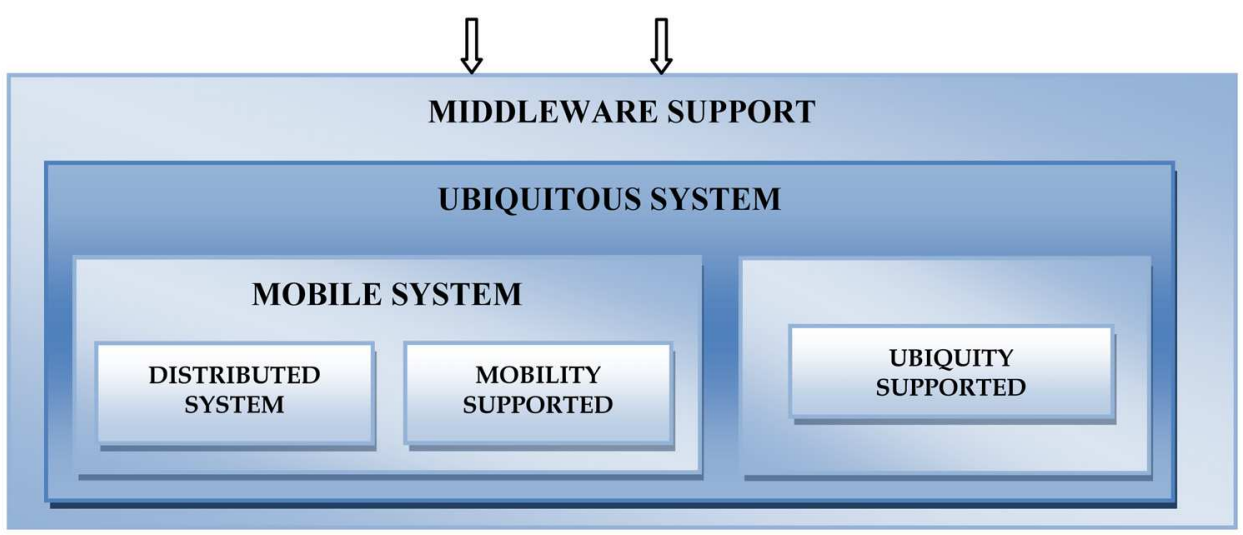

Fig. 5. Ubiquitous Computing (Saha and Mukherjee 2003).

\subsubsection{Ubiquitous medicine}

Health care seems to be an ideal application field for ubiquitous computing. Where else is the paradigm of "getting the right information at the right time at the right place of greater importance than in health care? Scenarios for application of ubiquitous computing are home care and monitoring, assistance for health professionals, and the self organization of health care institutions. Wearable systems and especially new man-machine interfaces are key technologies of ubiquitous computing in health care . Another key technology, namely RFID chips (Radio Frequency Identification) (Stanford, 2003), useful for realizing context awareness of ubiquitous computing solutions is already available and in use in several domains. These miniaturized chips allow the wireless transfer of data within a limited area around a special RFID reader and can be used to identify nearby people and objects.

Ubiquitous medical environments are those in which technological advances such as mobile devices and wireless networks bring new opportunities for access and interaction of its users, such as access of patient information. This information makes up the so-called Electronic Patient Record (EPR), allowing data about tests, facts and situations concerning the health of a patient to be accessed through multiple devices and heterogeneous networks.

Ubiquitous in medicine can be made to PEPs access to consolidated information on patients from anywhere in the network, allowing also cooperation between professionals regardless the time and space. In particular, medical ubiquitous environments must support the mobility of its employees, given that mobility is inherent in the medical profession. In addition to this nomadic nature of the doctor, it is important to consider that the medical activity is highly fragmented, i.e., shall be subject to interruptions during execution, as doctors spend little time at each location or activity. Thus, mechanisms that facilitate the professional's activities tend to improve their productivity. The importance of ubiquitous computing occurs not only when the main actor is the doctor, it can also be applied in the "world" of the patient, optimizing, for example, their monitoring system. Therefore the proposal shown in this chapter is not only a PEP system modernized but also the implementation of a unique module for tracking and monitoring patients. 


\subsubsection{Patient monitoring}

Patient monitoring systems comprise sensors, data communication, storage, processing, and presentation of medical data. These functions are performed both near the patient, in local surgery, or remotely at a health care infrastructure, e.g., a medical centre or a hospital. Patient monitoring systems can be used in a variety of health care scenarios ranging from paramedic, diagnostic, surgical, post-operative, and home surveillance situations. The systems must meet a high demand of flexibility since data may be produced outside a health care enterprise (Maghsudi et. Al, 1999) (Raffloer \& Wiggens, 1997). This requires specific measures in order to fulfill security, availability, privacy, and Quality of Service (QoS) demands. The properties are: a) mobility; b) outside hospital infrastructure; c) biomedical sensor networks in use; d) wireless channel.

\section{Example of an architecture with intelligent and mobile technology}

As an alternative to monitoring vital signs and conducting pre-diagnosis, object of this work, we consider that the systems for medical decision support using intelligent systems techniques combined with technologies that integrate mobility and portability in accessing processed information. The effects of this architecture can be significant, allowing a better interface, especially in the aspect of expert knowledge, communication and usability, important features for applications in medicine.

Thus, the specification of the application architecture considered environments with heterogeneous architectures and was based on: the acquisition of data from patient's vital signs monitoring; the use of intelligent systems techniques, especially fuzzy logic; information processing; and sending alerts through mobile devices.

The monitored environment, entitled Intelligent System for Monitoring Patients (ISMp) (Fig. 6), consists of: acquisition of data through a network of sensors placed in the patients' beds; pre-processing, where the preparation (filtering) and data selection are carried out; data processing and classification, where process is done through fuzzy logic in order to implement a pre-diagnosis to help the medical staff; data post-processing and preparation for sending alerts if any abnormality was detected; the information is sent to mobile devices that are registered in the environment, to support medical staff in decision making and implementation of relevant actions.

\section{a. Data acquisition}

To simulate the physiological data acquisition of patients (vital signs), we used the MIMIC (Multi-parameter Intelligent Monitoring for Intensive Care), which is a public database available on the Internet by the Physionet (PhisyoNet, 2010), in order to assist the work development facing the automation of hospital systems related to multiparametric monitoring of patients.

We used the software MATLAB (MathWorks) to read and load the data acquired from the biomedical devices.

The MIMIC has 74 records, with 20 to 40 hours of continuously recorded data each, related to patients admitted for medical, surgical and / or cardiac treatment in the ICU of Beth Israel Hospital in Boston. The data was obtained directly from the heart monitors installed in the beds and each record typically consists of hundreds of individual files. 


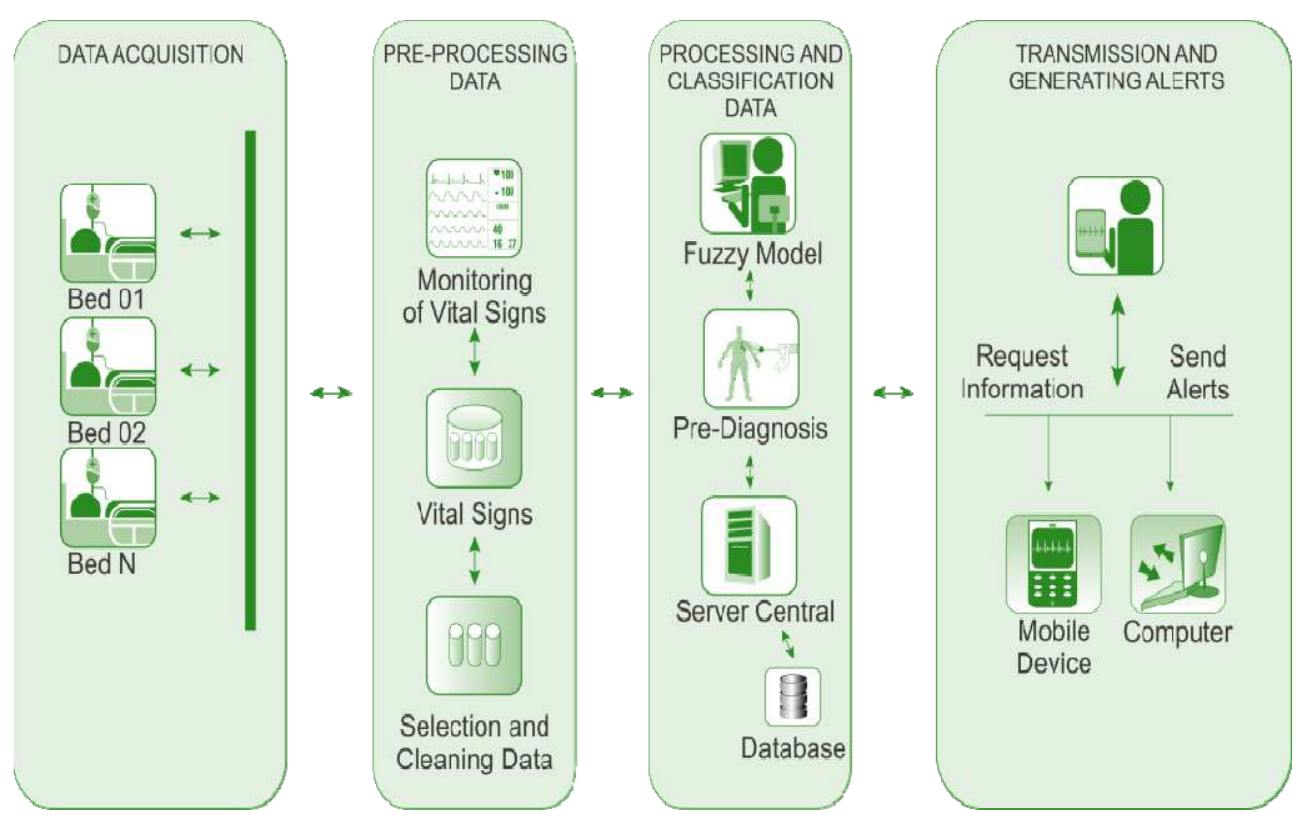

Fig. 6. Architecture of intelligent system for monitoring patients

It was observed that there are other notes in most of the records in the MIMIC database, including the QRS complex (which compose the ECG signal), as well as periodic alarms related to changes in the patient's condition, including heart and respiratory rate, oxygen saturation and systolic, diastolic and mean pressure shown in Fig. 7. In some records data from temperature sensors and cardiac output were also presented.

\section{b. Pre-processing data}

We carried out the extraction of the major physiologic signals that interfere directly in the clinical condition of patients with a stroke diagnosis (mean blood pressure, systolic blood pressure, diastolic blood pressure and oxygen saturation). It was observed that there are other physiological signals in the records of MIMIC database, such as the QRS complex (which compose the ECG signal) periodic alarms related to changes in the patient's condition; heart and respiratory rates; temperature; and cardiac output. The process of acquisition and validation of knowledge was done through weekly interviews during 2 (two) years, at the Promater Hospital, with the ICU medical staff. Thus, by pre-analysis performed together with medical specialists (general practitioner, cardiologist and neurologist) and nurses, the patients for validating the fuzzy model were selected. 


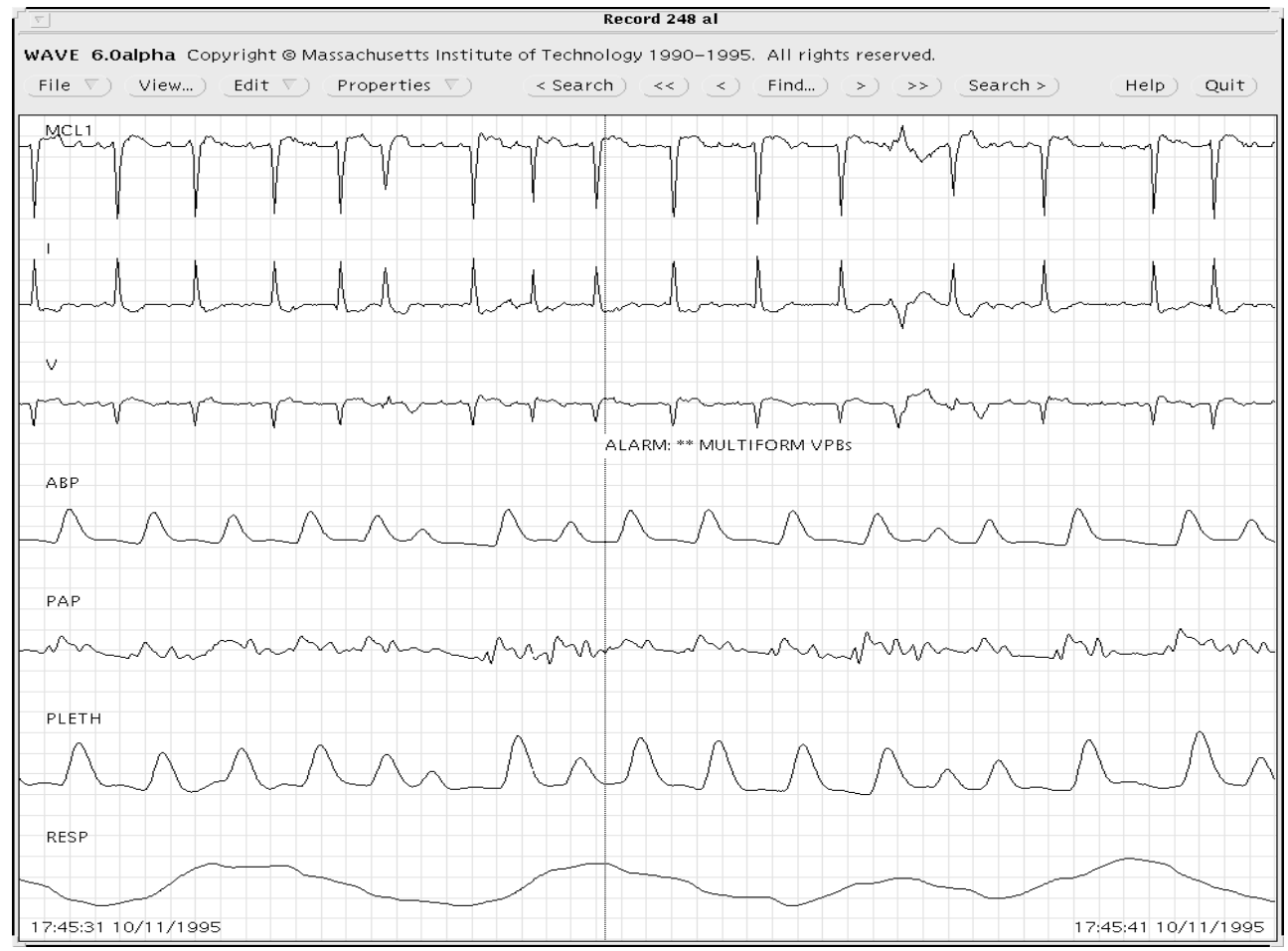

Fig. 7. A MIMIC sample (record 248)

\section{c. Processing and classification data}

In complex systems and processes, are required mechanisms for dealing with inaccurate information and reasoning and processing procedures to make them tractable. An effective strategy in these circumstances involves the acquisition, representation and processing of concepts described linguistically using fuzzy logic. In the literature studied and towards the proposed problem was found that the strategy of applying fuzzy logic could provide more benefits (acquisition of specialist's knowledge, generation of rules base, the process automation and increased accuracy of the pre-diagnosis) and satisfactory results. The implementation of intervention and control actions, in the model developed uses fuzzy logic, considering that it enables the capture of specialists' knowledge in the same way that lets you check the precise timing of the intervention and alarm. We developed a flowchart to assist the creation and use of a fuzzy system, called medical fuzzy system, shown in Fig. 8. 


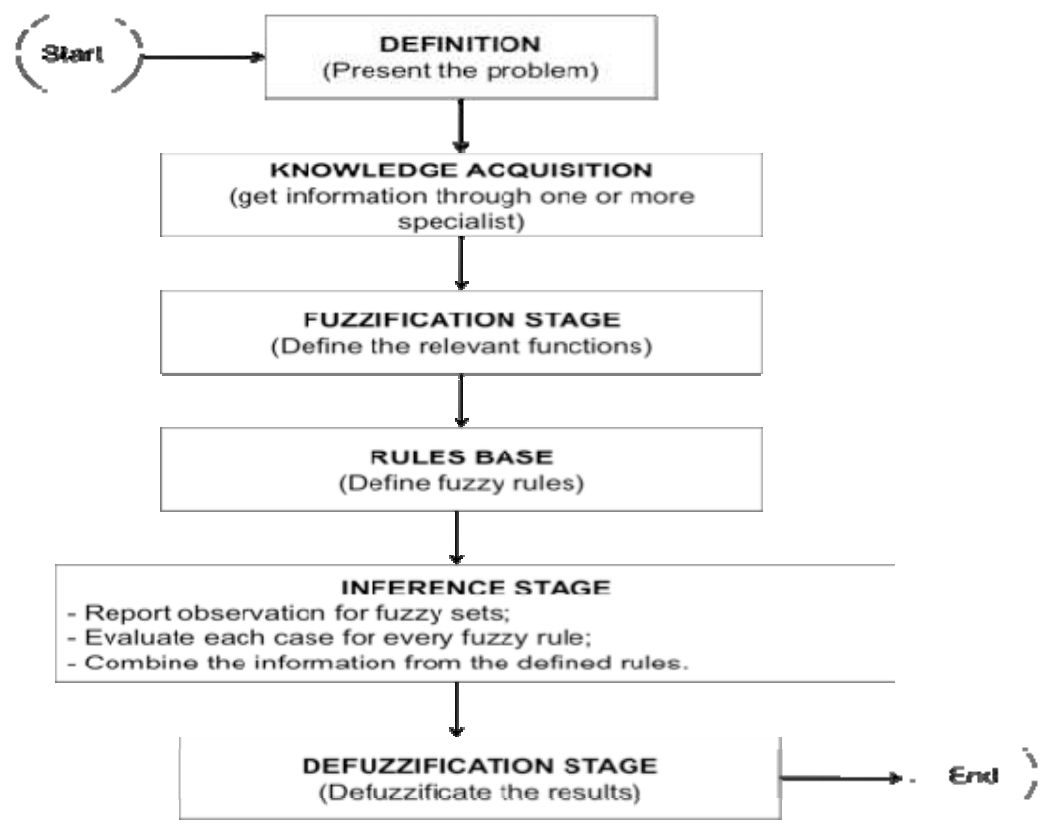

Fig. 8. Flowchart of creation and use of the fuzzy medical system

The fuzzy medical system definition and its stages (Fuzzification Stage, Inference Stage, Defuzzification Stage and Rules Base) are presented below.

1. Definition of fuzzy medical system: conditions of vital signs analysis, considering the parameters of normality and the defined fuzzy rules base, inferences in vital signs are made generating alarms from pre-diagnosis indicating abnormalities.

2. Obtain information from one or more specialists: the role of a specialist in the application to be modelled is of fundamental importance to collaborate in the construction of membership (relevants) functions for the entries description.

3. Define the fuzzy sets (membership functions) - Fuzzification Stage: in this stage the input variables are defined identifying to which fuzzy set(s) they belong to by assigning the respective degree to each relevance. The fuzzy sets represented by relevance functions should be set on the discourse universe in order to understand it completely. Thus, before the creation of fuzzy system, it is necessary to assemble the fuzzy sets (relevance functions) to be used in both fuzzification and defuzzification stages. The inputs of fuzzy system in question are the main vital signs (mean blood pressure and partial oxygen saturation) that were defined by the following relevance functions.

3.1 Mean Blood Pressure (MBP) Membership: MBP normal $\left(\mathrm{N}_{\mathrm{MBP}}\right)$ considering a domain (80-130), by the linguistic terms low $(\mathrm{L})$, normal $(\mathrm{N})$ and high $(\mathrm{H})$, respectively representing the bands, as illustrated in Fig. 9.

Fuzzy set of MAP:

Low MBP $\left(\mathrm{L}_{\mathrm{MBP}}\right)<80 \rightarrow \mathrm{L}_{\mathrm{MBP}}=\{(0,1),(60,1),(80,0)\}$;

Normal MBP $\left(\mathrm{N}_{\mathrm{MBP}}\right) 80-130 \rightarrow \mathrm{N}_{\mathrm{MPB}}=\{(75,0),(105,1),(130,0)\}$;

$\operatorname{High} \operatorname{MBP}\left(\mathrm{H}_{\mathrm{MBP}}\right)>130 \rightarrow \mathrm{A}_{\mathrm{MPB}}=\{(126,0),(138.7,1),(200,1)\}$. 
3.2 Partial Oxygen Saturation Membership POS 2 : $\mathrm{POS}_{2}$ normal ( $\mathrm{N}_{\mathrm{POS} 2}$ ) considering a domain (94-100), by linguistic terms, low (L) and normal (N), respectively, representing the bands, as illustrated in Fig. 10.

Fuzzy set of $\mathrm{POS}_{2}$ :

POS $_{2}$ baixa $\left(\mathrm{B}_{\mathrm{POS} 2}\right)<94 \rightarrow \mathrm{B}_{\mathrm{POS} 2}=\{(0,1),(90,1),(94,0)\}$;

$\mathrm{POS}_{2}$ normal $\left(\mathrm{N}_{\mathrm{POS} 2}\right) 94-100 \rightarrow \mathrm{N}_{\mathrm{POS} 2}=\{(89.2,0),(96.2,1),(100,0)\}$.

For this purpose, relevance functions were built from the direct method, the specialist informed all relevance functions data (values that represent each function and the degree of relevance, within the function of each) in order to set them explicitly. It is noteworthy that there are many relevance functions, but the most used in this fuzzy system were the triangular and trapezoidal as they better represent the functions according to the context.

4. Fuzzy rules definition (Rules Base): the rules base is assembled with the following structure: If <premises> Then<conclusion>. For the rules definition of the fuzzy medical system concerned, we could standardize the following structure:

- $\quad R:\left\{R_{1}, R_{2}, R_{3}, \ldots, R_{n}\right\} \rightarrow$ Set of rules;

- $\mathrm{SV}:\left\{\mathrm{SV}_{1}, \mathrm{SV}_{2}, \mathrm{SV}_{3}, \ldots, \mathrm{SV}_{\mathrm{n}}\right\} \rightarrow$ Set of vital signs;

- $\quad \mathrm{D}:\left\{\mathrm{D}_{1}, \mathrm{D}_{2}, \mathrm{D}_{3}, \ldots, \mathrm{D}_{\mathrm{n}}\right\} \rightarrow$ Set of possible diagnoses;

- P: $\{\mathrm{n}, \mathrm{l}, \mathrm{h}\} \rightarrow$ Parameterization of signals (normal, low and high).

\# Definição das Regras:

\#Rule: IF $\left.<\left(\mathrm{SV}_{1}, \mathrm{SV}_{2}, \mathrm{SV}_{3}, \ldots, \mathrm{SV}_{\mathrm{n}}\right)\right\rangle<\{n(\downarrow \uparrow), a(\uparrow), b(\downarrow)\}>$ And $/ \mathrm{Or}<\left(\mathrm{SV}_{1}, \mathrm{SV}_{2}, \mathrm{SV}_{3}, \ldots\right.$, $\left.\left.\mathrm{SV}_{\mathrm{n}}\right)><\{n(\downarrow \uparrow), a(\uparrow), b(\downarrow)\}\right\rangle$

THEN $<\mathrm{D}_{1}, \mathrm{D}_{2}, \mathrm{D}_{3}, \ldots, \mathrm{D}_{\mathrm{n}}>$

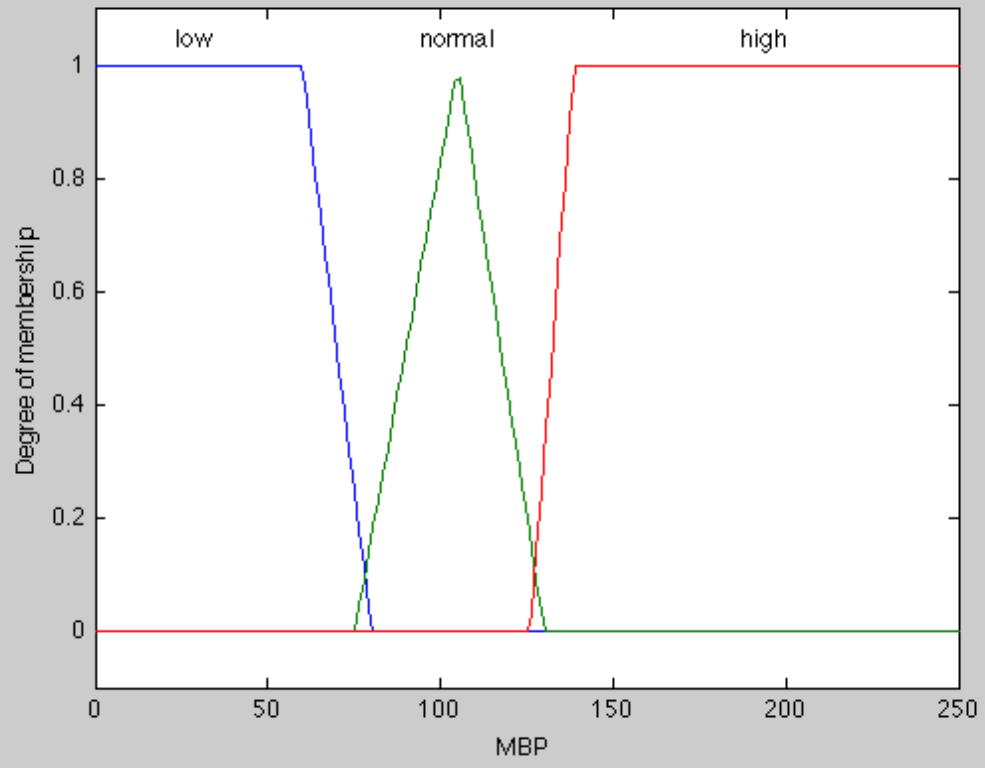

Fig. 9. Membership function of MBP 


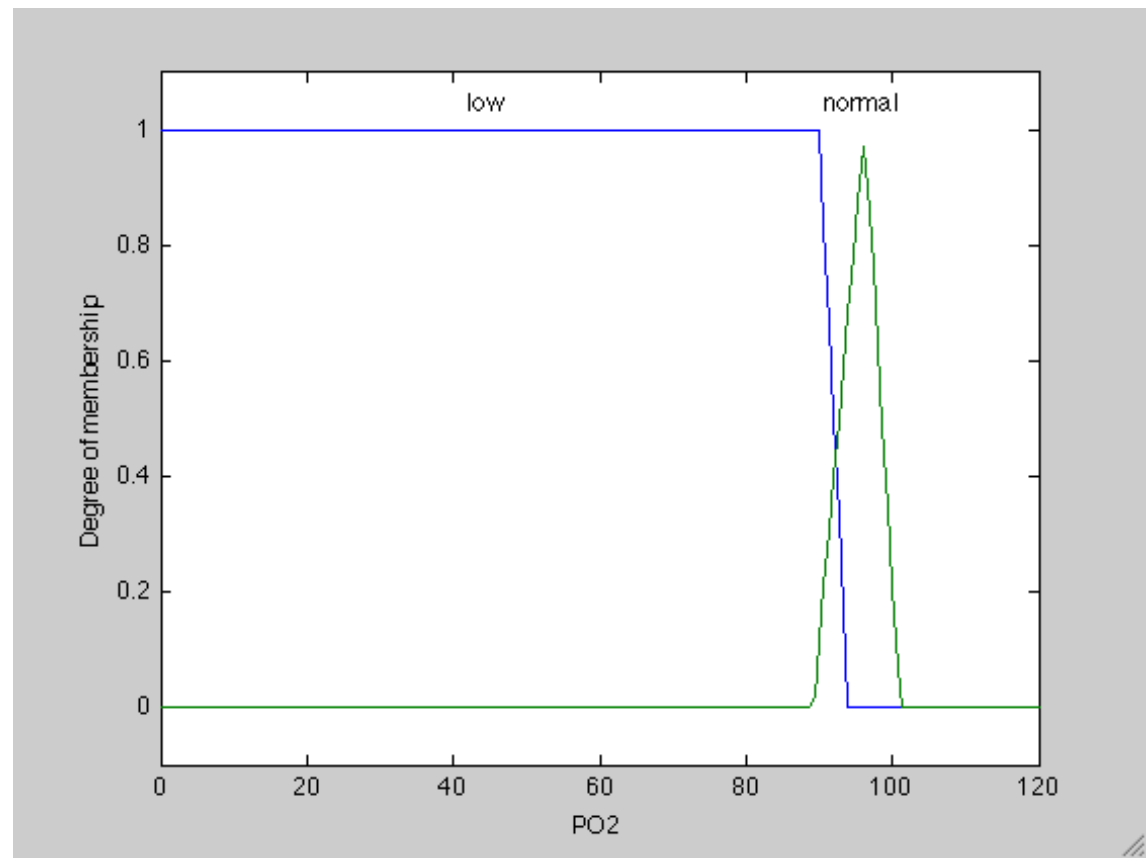

Fig. 10. Membership function of PO2

To exemplify, some rules for fuzzy medical system were set up, using two vital signs <premises>and 6 (six) situations as pre-diagnosis.

\# Rule 1: If low MAP and low POS2 then there is clinical instability.

IF MBP $\downarrow$ AND POS2 $\downarrow$ THEN UNSTABLE

\# Rule 2: If low MBP and normal SPO2 then low MBP.

IF MBP $\downarrow$ AND POS $\downarrow \downarrow \uparrow$ THEN $\downarrow$ MBP

\# Rule 3: If normal MBP and low SPO2 then hypoxemia.

IF MBP $\downarrow \uparrow$ AND POS $2 \downarrow$ THEN HYPOXEMIA

\# Rule 4: If normal MBP and normal SPO2 then stability in clinical condition.

IF MBP $\downarrow \uparrow$ AND POS $2 \downarrow \uparrow$ THEN STABLE

Rule \# 5: If high MBP and low SPO2 then instability in the clinical condition.

IF MBP $\uparrow$ AND POS2 $\downarrow$ THEN UNSTABLE

\# Rule 6: If high MBP and normal POS2 then high MBP

IF MBP $\uparrow A N D$ POS $2 \downarrow \uparrow$ THEN $\uparrow$ MBP

At this stage it is important that the amount of rules defined can cover all possible combinations of inputs and outputs of the problem proposed and that the consistency of the rules is reviewed to avoid contradictions. The rules base was developed from several meetings, discussions and interviews with the Promater hospital medical staff.

5. Reporting the comments to the fuzzy sets - Inference Stage: At this stage, the inputs are analyzed to generate the output fuzzy set with its respective degree of compatibility. In the proposed fuzzy medical system, we used the controller model 
proposed by Mamdani (Mamdani, 1974), where the activation function of each rule is set in and the inference system determines the degree of compatibility with the premise of the rules contained in the rules base. After that, it is determined which rules were activated and the relevance output function is applied, joining all activated output fuzzy sets and their degrees of compatibility in a single Output Set (OS). This OS represents all actions that are acceptable to the input set, each one with their level of compatibility. It is also assessed at this stage, each case for all fuzzy rules and the information combination is performed from the rules already defined in the Rules Base, as illustrated in Figure 11.

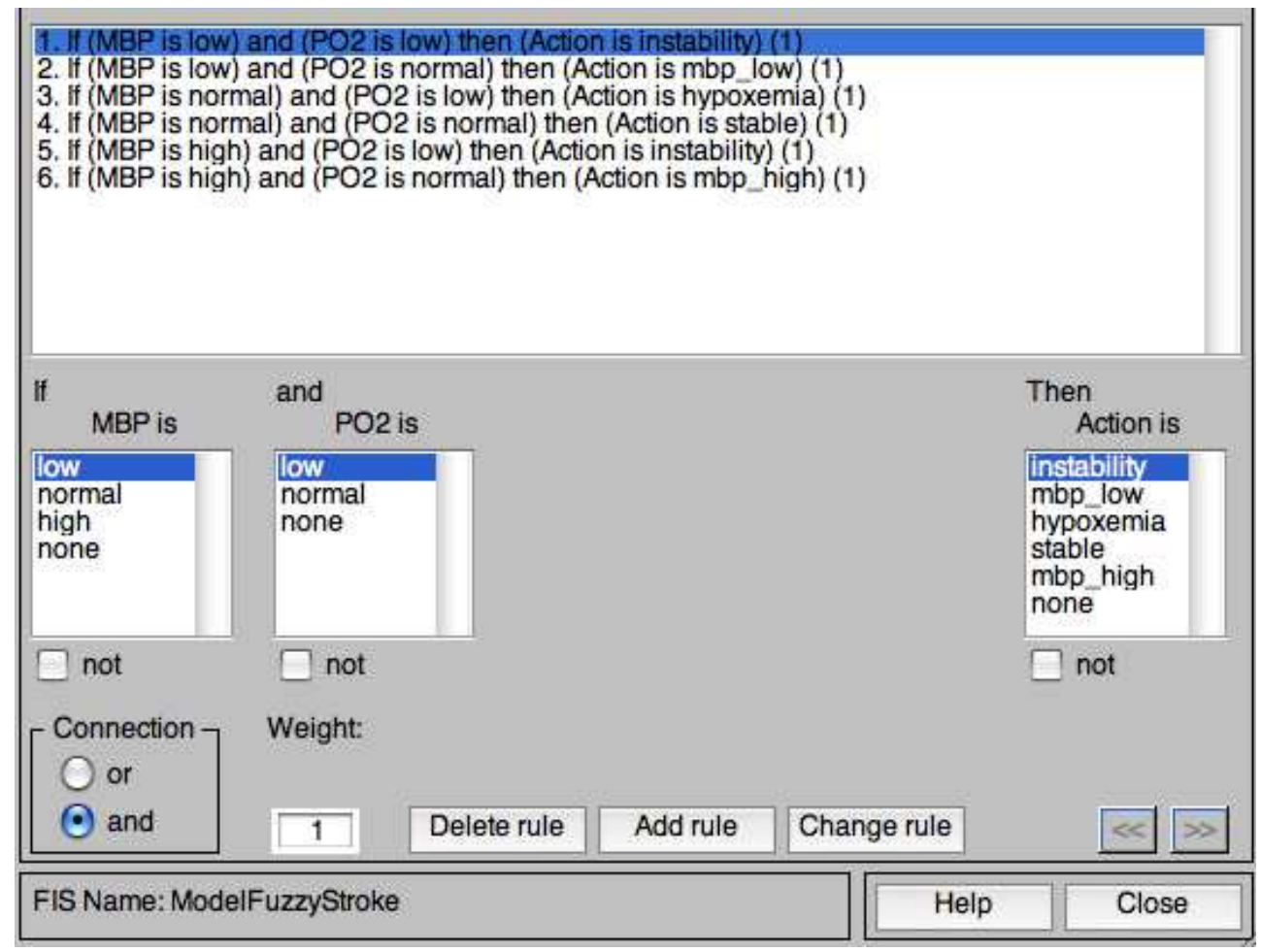

Fig. 11. Rules Base

6. Defuzzificate results - Defuzzification stage: this stage is used to generate a single numerical value, from all possible values contained in the fuzzy set obtained from the inference stage, to generate the control action. As a consequent action of the relations and variability of vital signs, was adopted for defuzzification the field (0-10), as illustrated in Table 2.

6.1 Action Relevance Function (A) - Defuzzification: representing the bands [ $<2.5$; 2.5-4.5; 4-6, 5, 5-8 and > 8] by linguistically terms instability, low MBP, hypoxemia, stable and high MBP. 


\begin{tabular}{|c|c|c|c|c|c|c|}
\hline Cases & MBP & SPO2 & Situation & Message & $\begin{array}{l}\text { What } \\
\text { should } \\
\text { be done }\end{array}$ & $\begin{array}{c}\text { Level } \\
\text { of urgency }\end{array}$ \\
\hline 1 & Low & Low & $\begin{array}{l}\text { Unstable } \\
\text { clinical } \\
\text { situation } \\
\text { (Instability) }\end{array}$ & $\begin{array}{l}\text { The patient's vital } \\
\text { signs are } \\
\text { altered }\end{array}$ & \multirow{3}{*}{$\begin{array}{l}\text { Send } \\
\text { alert to } \\
\text { the } \\
\text { doctor }\end{array}$} & $\begin{array}{l}\text { High } \\
\text { priority }\end{array}$ \\
\hline 2 & Low & Normal & Low MBP & $\begin{array}{c}\text { The patient's blood } \\
\text { pressure } \\
\text { is low }\end{array}$ & & $\begin{array}{l}\text { Low } \\
\text { priority }\end{array}$ \\
\hline 3 & Normal & Low & Hypoxemia & $\begin{array}{c}\text { Patient with } \\
\text { hypoxemia - } \\
\text { abnormal deficiency } \\
\text { of oxygen } \\
\text { concentration in } \\
\text { arterial blood }\end{array}$ & & $\begin{array}{l}\text { High } \\
\text { priority }\end{array}$ \\
\hline 4 & Normal & Normal & $\begin{array}{l}\text { Normal clinical } \\
\text { situation } \\
\text { (stable) }\end{array}$ & No alert & \multicolumn{2}{|c|}{ No abnormality } \\
\hline 5 & High & Low & $\begin{array}{l}\text { Unstable } \\
\text { clinical } \\
\text { situation }\end{array}$ & $\begin{array}{l}\text { The patient's vital } \\
\text { signs are } \\
\text { altered }\end{array}$ & \multirow{2}{*}{$\begin{array}{l}\text { Send } \\
\text { alert to } \\
\text { the } \\
\text { doctor }\end{array}$} & $\begin{array}{l}\text { Medium } \\
\text { priority }\end{array}$ \\
\hline 6 & High & Normal & High MBP & $\begin{array}{l}\text { The patient's blood } \\
\text { pressure is high }\end{array}$ & & $\begin{array}{l}\text { Low } \\
\text { priority }\end{array}$ \\
\hline
\end{tabular}

Table 2. Diagnostics and levels of urgency of clinical cases

\section{d. Alert generation and transmission}

From the level of urgency set in the rules base already defined, messages are sent to the medical team from the issuance of alarms for devices (mobile or not) and may, according to pre-defined settings, be sent to desktop screen, via email, SMS and others. The postprocessing and alerts sending is the architecture mechanism responsible for the control, sending and receiving messages between users and the architecture. This way, it is possible to create an effective communication system between a user (doctor) and the station (ICU). The main idea is that medical staff can connect to the centre with wireless network coverage in the hospital and thus receive on their device the alerts of possible changes in vital signs of monitored patients, as defined by Araujo (Araujo, 2009).

\section{Validation}

The simulations and validations of the proposed architecture have been conducted using MATLAB 2009a (student version) because of the tools available in this application for the development of models and the rapid visualization of the results obtained in the fuzzy system. 
The fuzzy model developed for pre-diagnosis of patients in the ICU performs the interaction between the captured values, operated by the inference rules in fuzzy expert system, triggering control actions, monitoring and helping to medical diagnosis. The model indicates the alarms in accordance with the Guideline (Jauch et al., 2010), prescribed and developed by the American Heart Association, playing the main features defined for issuing alerts. After obtaining the definition of normal values of vital signs, the relevance functions of the main variables that directly influence the clinical condition of ICU patients were acquired. For the generation of rules base was asked to physicians, considering the parameters of normality and abnormality, to indicate the diagnosis of each clinical case and their level of urgency as already illustrated in Table 2.

To validate the ISMp the patient's condition was monitored and classified in five situations that can significantly alter the clinical condition of ICU patients: 1-clinical instability (all signs altered), 2- low MBP; 3-hypoxemia; 4-stable, and 5- high-MBP.

We adopted the basis of fuzzy rules taking as background a normal MBP, considering a domain $[80,130]$, representing the bands $[<80,80-130]$ and $[>130]$ by linguistic terms low, normal and high, respectively; and partial oxygen saturation, considering a domain [94, 100], representing the bands $[<94$ and 94-100] by linguistic terms low and normal, respectively.

As the consequent action of signs relations and variability, it was adopted for defuzzification the domain [0, 10], representing the bands [<2.5; $2.5-4.5 ; 4-6 ; 5.5-8$ and $>8]$ by linguistic terms: instability, low MBP, hypoxemia, stable, high MBP, respectively.

Therefore, we used the vital signs selections required for the entry of fuzzy model constructing inference by relevance functions, rules base and already defined alarm conditions of vital signs for monitoring and support medical diagnosis in ICU inpatients.

An important step in this process was the extraction of data relevant to the model functioning, since the record is composed of many signs that are not used, which could interfere with the results and performance of the model. In the processing and sorting stage the results of the clinical diagnosis of patients' records were obtained through the model, as illustrated in Fig. 12.

In Fig. 12, we obtained the monitoring extract (query) of the patient identified by ID: 1662426 - 254NM, from $14 \mathrm{~h}$ : $06 \mathrm{~m}$ : $37 \mathrm{~s}$ of the day $24 / 11 / 1995$ to $14 \mathrm{~h}: 06 \mathrm{~m}$ : $57 \mathrm{~s}$ of the day $24 / 11 / 1995$. It was noted that monitoring is conducted every second and that in this interval the patient started unstable and passed to the state of Low MBP.

In the implementation of the model for monitoring and supporting the medical diagnosis of the clinical situation of the ICU patients was obtained a satisfactory result, with $96 \%$ accuracy (including the five situations planned) and $4 \%$ false alarms (due to various causes: from calibration of the equipment itself to body movements), according to analysis conducted by medical experts through the inferences made.

To this outcome measurements were available 100 (one hundred) inferences through forms (with patients' vital signs) so that physicians involved in this project could validate the prediagnosis provided by the proposed architecture and the fuzzy model. 


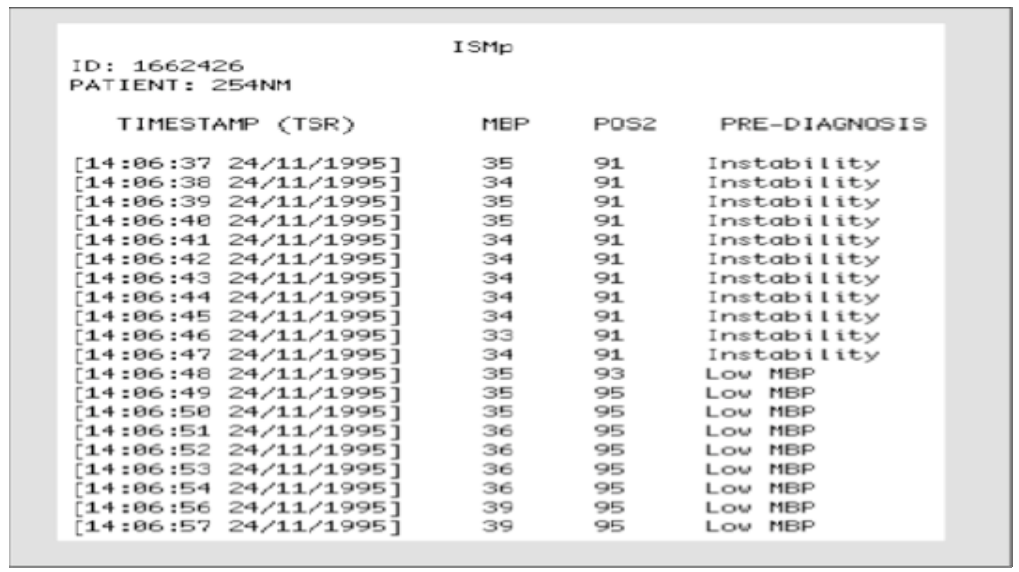

Fig. 12. Diagnosis of Register $254 \mathrm{~N}$

It should be noted that medical Specialists are part of the Promater Hospital who promptly answered the questionnaire separately and later joined together to discuss the results, they are both critical care physicians.

Analyses were performed by the answers provided by medical forms and discussions of results. In Fig. 13 you can view the overall performance evaluation of the model through the fuzzy output and results of three specialists. It was obtained from 100 hundred inferences: 92 (ninety-two) with similar diagnoses and 8 (eight) with different diagnoses.

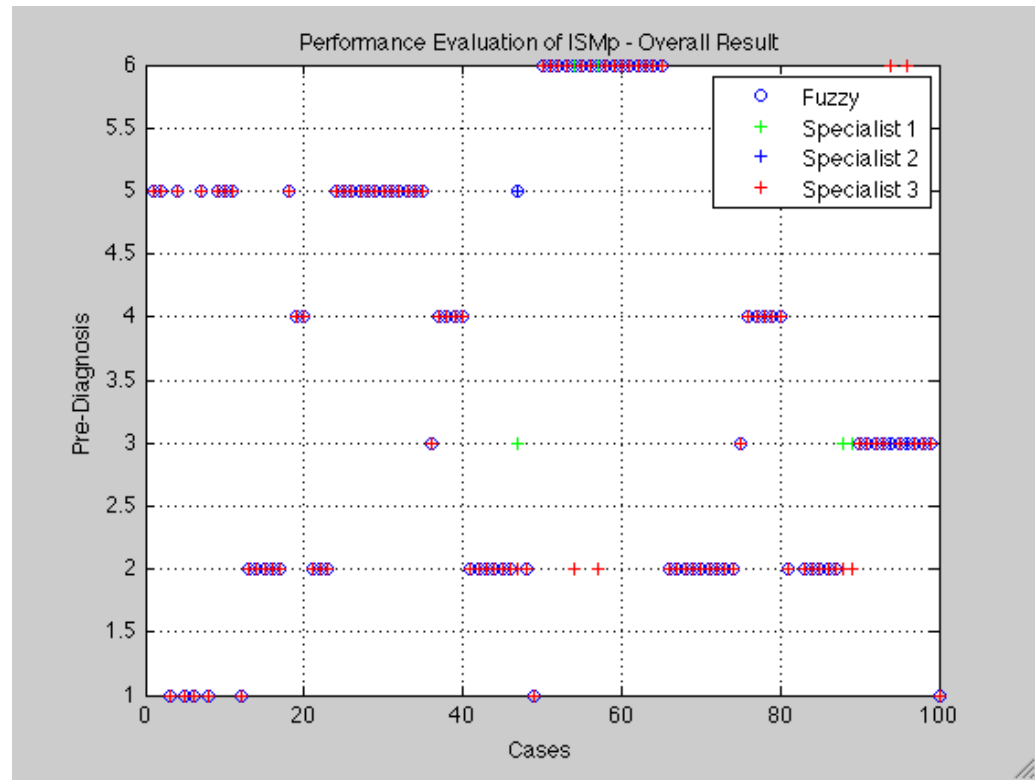

Fig. 13. Performance Evaluation of ISMp - Overall Result 
After discussing the results with the specialists it was verified that between the 8 (eight) with different diagnoses: 4 (four) the fuzzy inferred correctly, and 4 (four) diverged from each other.

\section{Conclusions and future plans}

This chapter presented a fuzzy model able to monitor and classify the condition of the vital signs of hospitalized patients, sending information to an alerts system according to the prediagnosis done helping the medical diagnosis.

Monitoring, processing, validation and testing of the fuzzy model were carried out using database with real data. It was also presented a simulation in order to evaluate its effectiveness, taking into account the pre-adjustment of the relevance functions in the pursuit of reducing false alarms. The use of fuzzy logic proved be for to the medical area very useful as a tool to assist specialists in this area.

Finally, from this study numerous possibilities for future work arise, such as: validation of the model in a real scenario and environment, confronting the real-time alarm generation and reception of messages being evaluated by the patient's physician, an increase of vital signs in the model, inclusion of specific alarms for each patient.

\section{References}

ABDI. Estudo Prospectivo: Equipamentos Médicos, Hospitalares e Odontológicos. / Agência Brasileira de Desenvolvimento Industrial, Centro de Gestão e Estudos Estratégicos. - Brasília: Agência Brasileira de Desenvolvimento Industrial, 2008.

Araújo, B.G.de, Leite, C.R.M., Valentim, R.A.de M., Brandão, G.B., Guerreiro, A.M.G. Middleware for remote healthcare monitoring. In Proceedings of the 6th international conference on Innovations in information technology (IIT'09). IEEE Press, Piscataway, NJ, USA, 66-70, 2009.

Begg, R.; Lai, Daniel T. H.; Palaniswami, M. Computational Intelligence in Biomedical Engineering (1st ed.). CRC Press, Inc., Boca Raton, FL, USA. 2007.

Barricelli, N. A. Esempi numerici di processi di evoluzione. Methodos, 45-68. 1954.

Fraser, A. Simulation of genetic systems by automatic digital computers I. Introduction. Australian Journal of Biological Sciences 10, 484-491. 1957

EDUMED, Projeto. URL: http://www.edumed.net/projetos/projeto-edumed.html (disponível na Internet, capturado em 10/12/2008).

Feng, D.D. Biomedical Information Technology. Series-Academic Press Series in Biomedical Engineering. Hardcover, Academic Press, 2007. ISBN:0123735831.

Figueiredo, C., Nakamura, E. (2003) "Computação Móvel: Novas Oportunidades e Novos Desafios". T\&C Amazônia.

Guimarães, R. Bases para uma política nacional de ciência, tecnologia e inovação em saúde. Ci Saúde Coletiva 2004 abril- junho; 9(2):375-87. 2.

Hanson, C. William; Marshall, Brayan E. “Artificial Intelligence applications in intensive care unit", Crit Care Med Vol. 29, No. 2, 2001.

Jauch, E.C., Cucchiara, B., Adeoye, O., Meurer, W., Brice, J., Chan, Y., Gentile, N., Hazinski, M.F. Journal of the American Heart Association. 2010 American Heart Association 
Guidelines for Cardiopulmonary Resuscitation and Emergency Cardiovascular Care. Circulation 2010: 122; S818-S828, Dallas, TX, USA. 2010.

Maghsudi, M., Hente, R., Neumann, C., Schachinger, U. and Nerlich, M. "Medical communication from emergency scenes using a notepad computer," J. Telemed. (1999) Telecare, vol. 5, pp. 249-252.

Mamdani, E. H. Application of fuzzy algorithms for control of simple dynamic plant, Procedings of IEEE 121(12), 1585-1588. 1974.

Marziale, MHP. Diretivas para o desenvolvimento de pesquisas em saúde no Brasil. Rev Latino-am Enfermagem 2004 julho- agosto; 12(4):1-2.

Mosby's - Medical Dictionary, 8th Edition, (C) 2009, Elsevier. Source: http://medicaldictionary.thefreedictionary.com/diagnosis. Accessed 8/04/2010.

Nof, S.Y. Springer Handbook of Automation. 1st. Springer Publishing Company, Incorporated, 2009.

Organização Mundial De Saúde - Oms. Disponível em: http://www.who.org. Acesso em: 18 de ago. 2009.

PhisyoNet. Disponível em: www.physionet.org. Accessed 8/04/2010.

Raffloer K. S. and Wiggens R. A. (1997), "Video in an ambulance (VIA): wireless multimedia for mobile ambulatory applications," in Proc. Amer. Telemed. Assoc. 2nd Annu. Meeting, Atlanta, GA, Apr. 3-6.

R-BITS. Revista Brasileira de Inovação Tecnológica em Saúde. Disponível em http://www.incubadora.ufrn.br/incubadora/index.php/reb/. 2011.

Rezende, S.O. Sistemas Inteligentes - Fundamentos e Aplicações. Manole, Barueri, SP, Brasil. 2003.

Rosenblatt, F. The perceptron: a probabilistic model for information storage and organization in the brain. Psychological Review 65, 386-408. 1958.

Saha, D.;Mukherjee, A. (2003) "Pervasive computing: A paradigm for the 21st century." Computer, IEEE Computer Society Press, Los Alamitos, CA, USA, v.36, n.3, p.2531,2003. ISSN 0018-9162.

Shavlik, J. and T. Dietterich. Readings in Machine Learning. The Morgan Kaufmann series in machine learning. San Mateo, CA: Morgan Kaufmann Publishers. 1990.

Shen, Y.; Xi, N.; Methil-Sudhakaran, N.; Mukherjee, R.; Zhu, D.; Cen, Z.; Mutka, M. W., Slomski, C. A., Apelgren, K. N. Internet based Tele-Diagnostic Interface for Breast Pathology. From Proceeding (564) Telehealth 2007. Montreal, QC, Canada: May 31 - Jun 1, 2007.

Stanford V. (2003) "Pervasive computing goes the last hundred feet with RFID systems." IEEE Pervasive Computing; 2: 9-14.

Sousa, J. P., Garlan, D. (2002) "Supporting User Mobility in Ubiquitous Computing Environments". Carnegie Mellon University.

Zadeh, L., T. Lin, and Y. Yao Data Mining, Rough Sets, and Granular Computing. Studies in Fuzziness and Soft Computing, vol. 95. Heidelberg: Physica-Verlag. 2002.

Zadeh, L.A. Fuzzy sets. Information and Control v. 8 ed .(3), p. 338-353. 1965.

Zadeh, L. Outline of a new approach to the analysis of complex systems and decision processes. IEEE Transactions on Systems, Man, and Cybernetics 8, 28-44. 1973. 
Weiser, M. (1991) "The Computer for the 21st Century". In: Scientific American. Volume: 265, Number: 3, Pages: 94-104, February.

Weiser, M.; Brown, J. (1996) Designing Calm Technology. PowerGrid Journal. Volume: 1, Number: 1, July. 


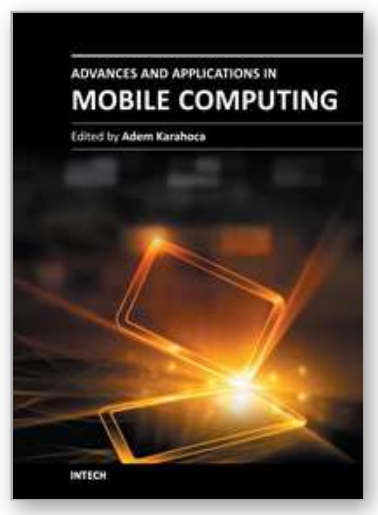

\author{
Advances and Applications in Mobile Computing \\ Edited by Associate Prof. Adem Karahoca
}

ISBN 978-953-51-0432-2

Hard cover, 224 pages

Publisher InTech

Published online 30, March, 2012

Published in print edition March, 2012

Advances and Applications in Mobile Computing offers guidelines on how mobile software services can be used in order to simplify the mobile users' life. The main contribution of this book is enhancing mobile software application development stages as analysis, design, development and test. Also, recent mobile network technologies such as algorithms, decreasing energy consumption in mobile network, and fault tolerance in distributed mobile computing are the main concern of the first section. In the mobile software life cycle section, the chapter on human computer interaction discusses mobile device handset design strategies, following the chapters on mobile application testing strategies. The last section, mobile applications as service, covers different mobile solutions and different application sectors.

\title{
How to reference
}

In order to correctly reference this scholarly work, feel free to copy and paste the following:

Cicilia Raquel Maia Leite, Glaucia R.M.A. Sizilio, Anna G.C.D. Ribeiro, Ricardo A.M. Valentim, Pedro F.R. Neto and Ana M.G. Guerreiro (2012). Mobile Technologies Applied to Hospital Automation, Advances and Applications in Mobile Computing, Associate Prof. Adem Karahoca (Ed.), ISBN: 978-953-51-0432-2, InTech, Available from: http://www.intechopen.com/books/advances-and-applications-in-mobile-computing/mobiletechnologies-applied-to-hospital-automation-

\section{INTECH}

open science | open minds

\author{
InTech Europe \\ University Campus STeP Ri \\ Slavka Krautzeka 83/A \\ 51000 Rijeka, Croatia \\ Phone: +385 (51) 770447 \\ Fax: +385 (51) 686166 \\ www.intechopen.com
}

\author{
InTech China \\ Unit 405, Office Block, Hotel Equatorial Shanghai \\ No.65, Yan An Road (West), Shanghai, 200040, China \\ 中国上海市延安西路65号上海国际贵都大饭店办公楼 405 单元 \\ Phone: +86-21-62489820 \\ Fax: +86-21-62489821
}


(C) 2012 The Author(s). Licensee IntechOpen. This is an open access article distributed under the terms of the Creative Commons Attribution 3.0 License, which permits unrestricted use, distribution, and reproduction in any medium, provided the original work is properly cited. 